\title{
Hydrogen isotopes in Quaternary mammal collagen from Europe
}

\author{
Darren R. Gröcke ${ }^{\mathrm{a}, *}$, Peter E. Sauer ${ }^{\mathrm{b}, *}$, Anne Bridault ${ }^{\mathrm{c}}$, Dorothée G. Drucker ${ }^{\mathrm{e}}$, \\ Mietje Germonpré ${ }^{\text {, }}$, Hervé Bocherens ${ }^{\mathrm{e}, *}$ \\ a Stable Isotope Biogeochemistry Laboratory (SIBL), Earth Sciences, Durham University, Durham DH1 3LE, UK \\ b Department of Geological Sciences, Indiana University, Bloomington, IN 47405, USA \\ c Equipe d'Archéologies Environnementales, Maison de l'Archéologie et de l'Ethnologie René Ginouvès, ArScAn-UMR 7041, 21 allée de l'Université, Nanterre, France \\ ' Earth and History of Life, RBINS, Vautierstraat 29, BE-1000, Brussel, Belgium \\ e Department of Geosciences, Biogeology and Senckenberg Center for Human Evolution and Palaeoenvironment, University of Tübingen, Hölderlinstrasse 12, 72074 Tübingen, Germany
}

\section{A R T I C L E I N F O}

\section{Article history:}

Received 1 August 2016

Received in revised form 4 November 2016

Accepted 7 November 2016

Available online $\mathrm{xxxx}$

\begin{abstract}
A B S T R A C T
Of the most abundant elemental constituents of organic matter, hydrogen has received the least attention due to its exchangeability with ambient water. The development of steam equilibration using two isotopically distinct waters can enable the user to calculate the proportion of exchangeable $\mathrm{H}$ and generate a $\delta^{2} \mathrm{H}$ value of the non-exchangeable $\mathrm{H}$. Three fossil faunal assemblages from Europe were selected in order to investigate collagen $\delta^{2} \mathrm{H}$ with respect to body mass, diet and to compare chronological periods in the Quaternary. $\delta^{15} \mathrm{~N}$ values in each suite of fauna show trophic level enrichment, a trend which was also observed in $\delta^{2} \mathrm{H}$ values. In the case of predatory species with lower $\delta^{15} \mathrm{~N}$ values than other carnivore species, the use of hydrogen isotopes could help to infer the consumption of prey with lower $\delta^{15} \mathrm{~N}$ values rather than a significant dietary contribution of plant foods. For example, a cave bear which exhibits low $\delta^{2} \mathrm{H}$ values are consistent with low $\delta^{15} \mathrm{~N}$ and therefore point to an herbivorous diet and not omnivory. The combination of $\delta^{2} \mathrm{H}$, with $\delta^{15} \mathrm{~N}$ and $\delta^{13} \mathrm{C}$, from archaeological and ecological studies of humans and fauna could help reconstruct prey preference; which is especially important when trying to distinguish the quantity of marine versus freshwater resources in diets. Relative to dietary influences, climate variability seems to be a minor control on $\delta^{2} \mathrm{H}$ in the faunal assemblages studied here.
\end{abstract}

C

\section{Introduction}

Stable isotope ratios of biologically important elements such as $\mathrm{C}, \mathrm{H}$, $\mathrm{N}$, and $\mathrm{O}$ have widespread applications in earth sciences and biology. Of the most abundant elemental constituents of organic matter, hydrogen has received the least attention due to several factors (i.e. exchangeable hydrogen) that have, until recently, complicated the analysis and interpretation of hydrogen isotope data derived from organic materials. Recent advances in analytical techniques (Sauer et al., 2009) for organic hydrogen have facilitated the analysis of hydrogen isotope ratios $\left(\delta^{2} \mathrm{H}\right)$ from organic matter to be explored.

Hydrogen in organic matter can occupy many different chemical positions, and since it is loosely bound to $\mathrm{O}$ and $\mathrm{N}$, the hydrogen can exchange readily with ambient water. For this reason, the ${ }^{2} \mathrm{H} /{ }^{1} \mathrm{H}$ ratio of those hydrogen pools provides more information about the recent exposure to water vapour (e.g., laboratory air) than about primary environmental and/or biological conditions. In order to remove these affects the $\mathrm{O}$ - and $\mathrm{N}$-bound hydrogen must either be removed or

\footnotetext{
* Corresponding authors.

E-mail addresses: d.r.grocke@durham.ac.uk (D.R. Gröcke), pesauer@indiana.edu (P.E. Sauer), herve.bocherens@uni-tuebingen.de (H. Bocherens).
}

replaced. Chemical removal, nitration of cellulose is labour-intensive and requires a large initial sample. An alternative approach is to control the exchangeable hydrogen by means of exposure to a vapour or vapours of known isotopic composition(s) that has been adapted by various labs for continuous-flow IRMS approaches (Sauer et al., 2009; Meier-Augenstein et al., 2011; Wassenaar et al., 2015). A steam equilibrator enables the simultaneous analysis of 10 samples (in triplicate) of protein (Sauer et al., 2009).

Previous research on hydrogen isotope ratios in protein (Cormie et al., 1994) has revealed a strong climatic control in parallel to strong ${ }^{2} \mathrm{H} /{ }^{1} \mathrm{H}$ gradients in precipitation. Because many migratory bird (and some butterfly) species cross climatic gradients, ${ }^{2} \mathrm{H} /{ }^{1} \mathrm{H}$ ratios of non-exchangeable hydrogen of feather and insect keratin has been used to document migration patterns and regional hydrological/climatic conditions (Hobson et al., 1999; Gröcke et al., 2006, 2010; van Hardenbroek et al., 2012). Hydrogen isotope ratios in collagen from large herbivores, for example North American bison, have shown to vary through the Holocene and track changes in moisture availability and temperature (Leyden et al., 2006).

In addition to climatic influences, trophic level may also have an influence due to metabolic effects and inefficiencies in nutrient transfer up food chains; higher trophic level consumers exhibit higher $\delta^{15} \mathrm{~N}$ 


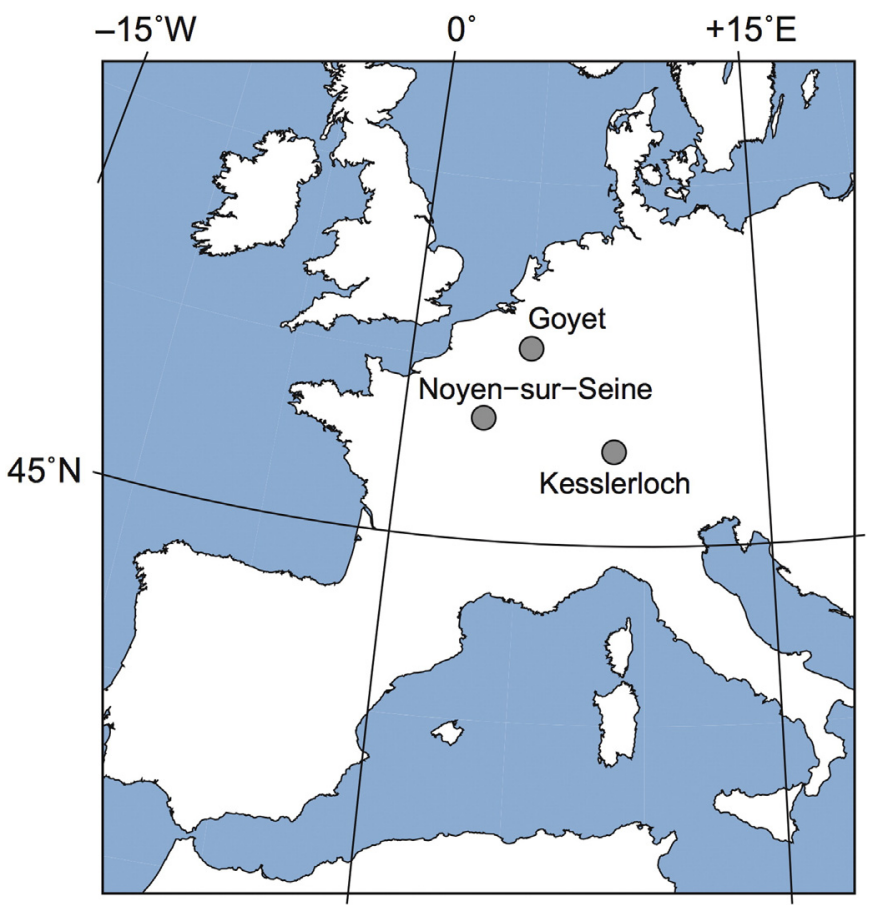

Fig. 1. Map of sample locations investigated in this study.

values than their prey (e.g., Bocherens and Drucker, 2003). A study of several European archaeological sites showed a progressive enrichment in bone collagen $\delta^{2} \mathrm{H}$ from herbivores to omnivores (pigs) to carnivores (humans), with an enrichment factor of $20 \%$ o to $50 \%$ (Birchall et al., 2005; Reynard and Hedges, 2008). Additionally, 12 mammalian species from a limited geographic area in Indiana, suggests that body size and respiration rates may also influence bone collagen $\delta^{2} \mathrm{H}$ (Topalov et al., 2013).

In this study, we have selected three faunal assemblages including herbivores and carnivores of different sizes that lived under different climatic conditions from Europe (Fig. 1). The aim of this study was to decipher the relative role of climate, trophic level and physiology on $\delta^{2} \mathrm{H}$ in archaeological large mammals to determine its application for studying ancient ecosystems.

\section{Materials and methods}

Three different fossil faunal assemblages from Europe, that include herbivorous and carnivorous taxa, have been sampled: Goyet Cave
(Belgium; 40-27 kyrs BP), Kesslerloch (Switzerland; 14-12 kyrs BP) and Noyen-sur-Seine (France; $~ 8$ kyrs BP) (Fig. 1). Information on each of these specific sites is provided in the Supplementary information.

Hydrogen isotope measurements were made by exposing two sets of the same collagen sample to a vapour under controlled temperature at $115{ }^{\circ} \mathrm{C}$ (Sauer et al., 2009): snow that was collected in Durham in $2010\left(\delta^{2} \mathrm{H}=-60 \%\right)$ and $\mathrm{a}^{2} \mathrm{H}$-spiked water made at Durham $\left(\delta^{2} \mathrm{H}=+1150 \%\right.$ ). The equilibrated samples were analysed using a Thermo TC/EA coupled with a Delta V Advantage IRMS at Durham University. The $\delta^{2} \mathrm{H}$ values are expressed against Vienna Standard Mean Ocean Water (VSMOW) by calibrated international standards: IAEA$\mathrm{CH}-7$ (polyethylene foil), IAEA-CH-3 (cellulose) and $n \mathrm{C}_{36}$ (Arndt Schimmelmann, Indiana), including an internal standard, JTNP-1 (deer collagen). Standard deviation of the standards and samples were typically $<2 \%$ ( $2 \mathrm{SD}$ ). For more details regarding fractionation factor and calculation of exchangeable hydrogen we refer the reader to Sauer et al. (2009) whose methods were followed stringently in this study.

\section{Results and discussion}

The $\delta^{2} \mathrm{H}$ values of terrestrial mammals exhibited a wide range of values in each site; between $-40.4 \%$ o to $-99.9 \%$ in Goyet Cave, $-38.9 \%$ o to $-111.2 \%$ in Kesslerloch, and $-37.2 \%$ o to $-78.2 \%$ in Noyen-sur-Seine (see Supplementary information, Table S1, S2, S3). The single freshwater predator (otter) analysed in this study from Kesslerloch had the highest $\delta^{2} \mathrm{H}$ value of $+1.3 \%$. In all sites there was no obvious relationship between $\delta^{2} \mathrm{H}$ and body size within a trophic group.

From Goyet Cave, most carnivores and herbivores were well separated, with carnivores having less negative $\delta^{2} \mathrm{H}$ values than herbivores, except for the three horses (Figs. 2, 3). Wolves, which had lower $\delta^{15} \mathrm{~N}$ than other carnivores (e.g., lions and hyenas) at this site, nonetheless exhibited $\delta^{2} \mathrm{H}$ as high as those carnivores. Although the mammoth, an herbivorous species, exhibited high $\delta^{15} \mathrm{~N}$ values compared to other herbivores but similar to carnivores, their $\delta^{2} \mathrm{H}$ values were within the range of other herbivores at Goyet Cave, albeit in a higher part of the range (Figs. 2, 3). The adult cave bears had $\delta^{15} \mathrm{~N}$ and $\delta^{2} \mathrm{H}$ values similar to those of other herbivores. One particular case was the newborn cave bear, with a very high $\delta^{15} \mathrm{~N}$ value and a very low $\delta^{2} \mathrm{H}$ value.

From Kesslerloch, most terrestrial carnivores exhibited higher $\delta^{2} \mathrm{H}$ values than herbivores (Figs. 2, 3). However, wolves exhibited $\delta^{2} \mathrm{H}$ that overlapped those herbivores with the highest $\delta^{2} \mathrm{H}$ even though their $\delta^{15} \mathrm{~N}$ are clearly suggesting carnivory. Fox and lynx, with slightly lower $\delta^{15} \mathrm{~N}$ than other carnivores had, nonetheless, high $\delta^{2} \mathrm{H}$ values: a result that precludes omnivory for the fox. The differences in $\delta^{15} \mathrm{~N}$ and $\delta^{2} \mathrm{H}$ between carnivore species are most likely linked to differences in

\begin{tabular}{|c|c|c|}
\hline$\bullet$ & Panthera spelaea (cave lion) & Mammuthus primigenius (woolly mammoth) \\
\hline - & Canis lupus (gray wolf) & Coelodonta antiquitatis (woolly rhinoceras) \\
\hline$\Delta$ & Crocuta crocuta spelaea (cave hyaena) & $\Delta$ Equus ferus (wild horse) \\
\hline$\bullet$ & Gulo gulo (wolverine) & - Bison priscus (steppe bison) \\
\hline$\bullet$ & Lynx lynx (lynx) & - Rangifer tarandus (reindeer) \\
\hline$\bullet$ & Vulpes vulpes (red fox) & Lepus timidus (hare) \\
\hline$\bullet$ & Lutra lutra (otter) & Spermophilus rufescens (ground squirrel) \\
\hline घ & Sus scrofa (wild boar) & - Cervus elaphus (red deer) \\
\hline & Ursus spelaeus (cave bear) & Capreolus capreolus (roe deer) \\
\hline & & B Bos primigenius (aurochs) \\
\hline
\end{tabular}



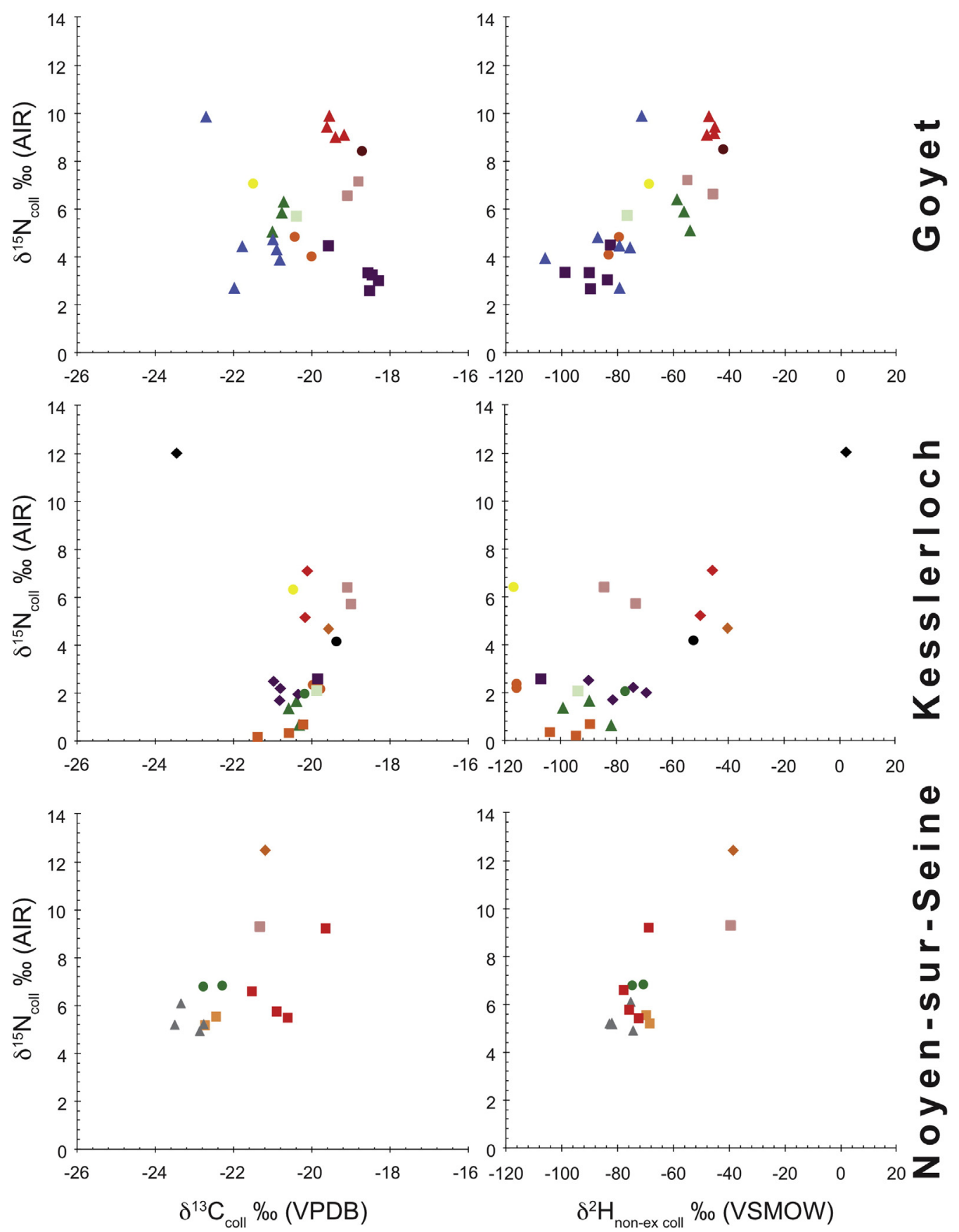

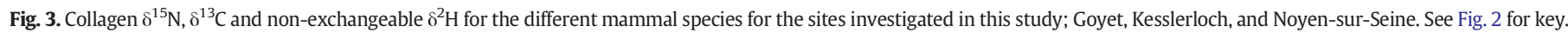

prey choice. The mammoth has a $\delta^{15} \mathrm{~N}$ value similar to carnivores, but exhibited very low $\delta^{2} \mathrm{H}$ values that are clearly within the range of other herbivores. These elevated $\delta^{15} \mathrm{~N}$ values are likely due to eating of high $\delta^{15} \mathrm{~N}$ plants (Schwartz-Narbonne et al., 2015; Naito et al., 2016).

From Noyen-sur-Seine, there was a clear distinction between carnivores and herbivores with an average between 30\% to $40 \%$ o less depleted than the herbivores (Figs. 2, 3). All boars exhibited similar $\delta^{2} \mathrm{H}$ values, although one of the boars had a very high $\delta^{15} \mathrm{~N}$ value. Surprisingly, the $\delta^{2} \mathrm{H}$ values of herbivores from the Holocene site of Noyen-surSeine are not statistically different from those of Pleistocene mammals from Kesslerloch and Goyet - even though mammals from both Pleistocene sites lived under different climatic conditions (i.e. colder) than those of the Holocene site.

\subsection{Hydrogen isotopes and trophic levels}

Hydrogen isotope ratios could be used to test omnivory in several mammalian species. All boars from Noyen-sur-Seine exhibited similar $\delta^{2} \mathrm{H}$ values, although one specimen had a very high $\delta^{15} \mathrm{~N}$ value. This may indicate that varying $\delta^{15} \mathrm{~N}$ values in boar were not indicative of omnivory, or that omnivory was not linearly reflected in $\delta^{2} \mathrm{H}$ values. An alternative explanation could be that the digestive physiology for omnivory is more important than actual diet consumed. Probably these questions need to be investigated further with experimental or modern ecosystem data.

Interestingly, the low $\delta^{2} \mathrm{H}$ values of cave bears from Goyet are consistent with their low $\delta^{15} \mathrm{~N}$ and point to an herbivorous diet, in contrast 
with suggestions for an omnivorous diet based on teeth microwear analysis (Peigné et al., 2009). The difference between isotope values and tooth wear could be due to biases in the modern reference dataset used in the latter approach (Bocherens, 2009; Münzel et al., 2014).

In the case of predators with lower $\delta^{15} \mathrm{~N}$ values than other carnivore species, the use of hydrogen isotopes could help to infer the consumption of prey with lower $\delta^{15} \mathrm{~N}$ values rather than a significant contribution of plant food resources; as shown in the case of the wolf in Goyet Cave and the red fox in Kesslerloch. This study indicates that $\delta^{2} \mathrm{H}$ values seem to be a useful tool for reconstructing prey preference in combination with $\delta^{13} \mathrm{C}$ and $\delta^{15} \mathrm{~N}$. The potential to discriminate between omnivorous carnivores may be more powerful when using hydrogen isotopes, as well as distinguishing between carnivore members with predatory habits, or vegetarian ones, such as in cave bears. In addition, our data confirm that using hydrogen isotopes to track carnivore origins may be complicated by interfering factors (Pietsch et al., 2011).

Several datasets (Birchall et al., 2005; Reynard and Hedges, 2008; Topalov et al., 2013) are now available that show the difference between herbivore and carnivore $\delta^{2} \mathrm{H}$ values. All studies indicate a positive enrichment between herbivore and carnivores: note, Reynard and Hedges (2008) is a study that compared herbivores with humans. The data show enrichments with a high degree of variability and is most likely due to the sample location and the types of herbivores and carnivores used for comparison (Table S4).

\subsection{Hydrogen and physiology - hibernation}

The impact of hibernation seems very significant on the $\delta^{2} \mathrm{H}$ values of cave bears in this study. The newborn cave bear exhibited a very high $\delta^{15} \mathrm{~N}$ value together with a very depleted $\delta^{2} \mathrm{H}$ value. Female cave bears give birth to their cubs during hibernation and the foetus developed entirely while the female is in hibernation (e.g., Germonpré, 2004). Carbon and nitrogen isotopic signatures of newborn cave bear cubs exhibit values indicative of hibernation. Reynard and Hedges (2008) show that milk should be enriched in $\delta^{2} \mathrm{H}$ relative to drinking water in terrestrial mammals. In marine mammals, collagen $\delta^{2} \mathrm{H}$ values were also depleted in sea lion pups compared to sea lion adults; a feature that was interpreted as reflecting the consumption of lipid-rich milk diet for the young sea lions (Topalov et al., 2013). The difference in $\delta^{15} \mathrm{~N}$ values between newborn and adult cave bears is too high to reflect milk consumption alone. We hypothesize that the process of hibernation has a significant effect on $\delta^{2} \mathrm{H}$ values in cave bears.

\subsection{Collagen hydrogen isotopes as a climatic indicator}

The use of large mammal collagen $\delta^{2} \mathrm{H}$ values for palaeoclimatic reconstruction does not seem very promising (Fig. 4). Surprisingly, the $\delta^{2} \mathrm{H}$ values of the herbivores from the Holocene site of Noyen-surSeine were not very different from those of Pleistocene mammals from Kesslerloch and Goyet (Fig. 4), although mammals from both Pleistocene sites lived under colder conditions than those from the Holocene site. The different geographical locations cannot explain the isotopic pattern since all three sites yielded $\delta^{2} \mathrm{H}$ values between $-50 \%$ and $-58 \%$ for the annual average isotopic values of local modern precipitation (calculated from OIPC, http://wateriso.utah.edu/ waterisotopes/pages/data_access/oipc.html). It is possible that greater aridity during the Pleistocene may have increased the $\delta^{2} \mathrm{H}$ values of drinking water used by mammals in Goyet and Kesslerloch, and partly compensated for the lower $\delta^{2} \mathrm{H}$ values due to lower temperatures compared to Noyen-sur-Seine. In Kesslerloch, both wolves and bovids exhibit lower $\delta^{2} \mathrm{H}$ values compared to the members of the same species from Goyet and Noyen-sur-Seine. The cause for this may be due to the influence of low deuterium water flowing from the Alps in Kesslerloch. In any case, it seems that the use of hydrogen isotope composition in large mammal bone collagen for palaeoclimatological reconstruction will not be simple.

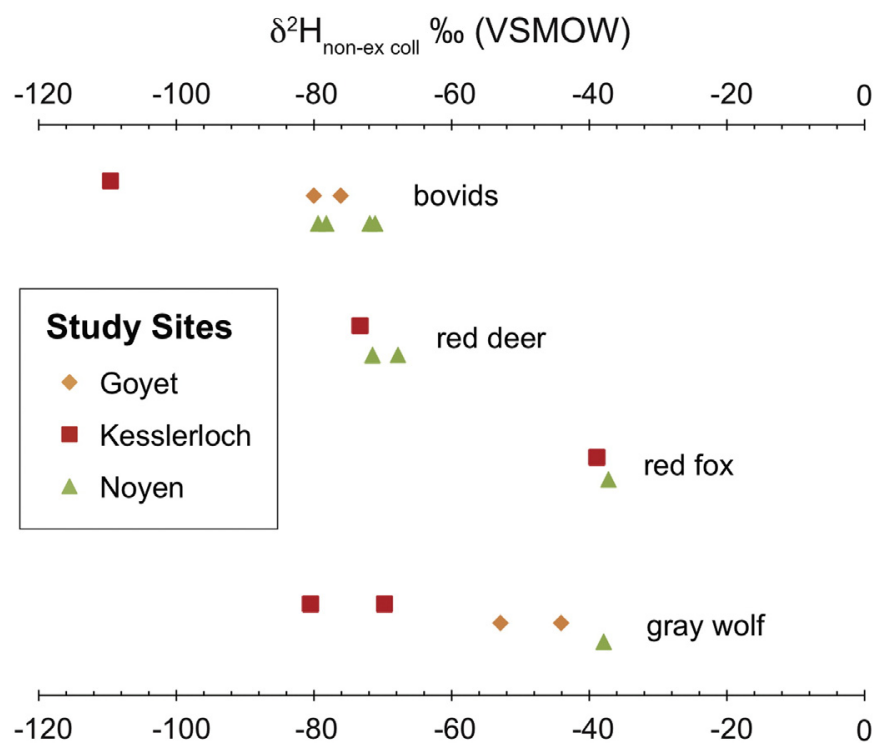

Fig. 4. Collagen non-exchangeable $\delta^{2} \mathrm{H}$ for similar mammal species across three Quaternary time intervals; Goyet (40-27 kyrs BP), Kesslerloch (14-12 kyrs BP), and Noyen-sur-Seine ( $\sim 8$ kyrs BP).

\subsection{Distinction between terrestrial and freshwater trophic webs}

In the present study, it was possible to distinguish freshwater from terrestrial food webs. The very clear distinction observed between the freshwater carnivore and the terrestrial carnivores in Kesslerloch is in contrast with previously published data from modern ecosystems, where carnivores from terrestrial and aquatic ecosystems exhibited similar $\delta^{2} \mathrm{H}$ values (Birchall et al., 2005). Several explanations could be explored to explain this discrepancy: (1) samples in Birchall et al. (2005) were sampled from across the UK; (2) Birchall et al. (2005) used a different method for removing exchangeable hydrogen in that only one calibration water was used; and (3) the mammals analysed in Birchall et al. (2005) had variable body mass, which may affect their $\delta^{2} \mathrm{H}$ (Topalov et al., 2013).

We highly recommend that additional studies are required that aim at establishing a valid and comprehensive reference database to test the possibility to distinguish freshwater from terrestrial food webs - a distinction that is very important in several archaeological fields, such as radiocarbon dating (i.e. Cook et al., 2001), the role of subsistence in human evolution (e.g., Drucker and Bocherens, 2004; Richards and Trinkaus, 2009), and dietary changes between successive archaeological cultures (e.g., Boric et al., 2004; Lightfoot et al., 2011).

\section{Appendix A. Supplementary data}

Supplementary data to this article can be found online at http://dx. doi.org/10.1016/j.jasrep.2016.11.020.

\section{References}

Birchall, J., O'Connell, T.C., Heaton, T.H.E., Hedges, R.E.M., 2005. Hydrogen isotope ratios in animal body protein reflect trophic level. J. Anim. Ecol. 74, 877-881.

Bocherens, H., 2009. Dental microwear of cave bears: the missing temperate/boreal vegetarian "carnivore". Proc. Natl. Acad. Sci. 106, E133.

Bocherens, H., Drucker, D., 2003. Trophic level isotopic enrichments for carbon and nitrogen in collagen: case studies from recent and ancient terrestrial ecosystems. Int. J. Osteoarchaeol. 13, 46-53.

Boric, D., Grupe, G., Peters, J., Mikić, Ž., 2004. Is the Mesolithic-Neolithic subsistence dichotomy real? New stable isotope evidence from the Danube Gorges. Eur. J. Archaeol. 7, 221-248.

Cook, G.T., Bonsall, C., Hedges, R.E.M., McSweeney, K., Boroneant, V., Pettitt, P.B., 2001. A freshwater diet-derived ${ }^{14} \mathrm{C}$ reservoir effect at the Stone Age sites in the iron. Gates Gorge. Radiocarb. 43, 453-460. 
Cormie, A.B., Schwarcz, H.P., Gray, J., 1994. Relation between hydrogen isotope ratios of bone collagen and rain. Geochim. Cosmochim. Acta 58, 377-391.

Drucker, D.G., Bocherens, H., 2004. Carbon and nitrogen stable isotopes as tracers of diet breadth evolution during Middle and Upper Palaeolithic in Europe. Int. J. Osteoarchaeol. 14 (3-4), 162-177.

Germonpré, M., 2004. Two cave bear assemblages from Goyet (Chamber A, horizon 1 and 3), Belgium. Rev. Paléobiol. 23, 855-875.

Gröcke, D.R., Schimmelmann, A., Elias, S., Miller, R.F., 2006. Stable hydrogen isotope ratios in beetle chitin: preliminary European data and re-interpretation of North American data. Quat. Sci. Rev. 25, 1850-1864.

Gröcke, D.R., van Hardenbroek, M., Sauer, P., Elias, S., 2010. Hydrogen isotope studies in beetle chitin. In: Gupta, S.N. (Ed.), Chitin: Formation and Diagenesis. Springer, New York, pp. 105-116.

Hobson, K.A., Wassenaar, L.I., Taylor, O.R., 1999. Stable isotopes ( $\delta \mathrm{D}$ and $\left.\delta^{13} \mathrm{C}\right)$ are geographic indicators of natal origins of monarch butterflies in eastern North America. Oecologia 120, 397-404.

Leyden, J.J., Wassenaar, L.I., Hobson, K.Q., Walker, E.G., 2006. Stable hydrogen isotopes of bison bone collagen as a proxy for Holocene climate on the Northern Great Plains. Palaeogeogr. Palaeoclimatol. Palaeoecol. 239, 87-99.

Lightfoot, E., Boneva, B., Miracle, P.T., Slaus, M., O'Connell, T.C., 2011. Exploring the Mesolithic and Neolithic transition in Croatia through isotopic investigations. Antiquity 85 , 73-86.

Meier-Augenstein, W., Chartrand, M.M.G., Kemp, H.F., St-Jean, G., 2011. An inter-laboratory comparative study into sample preparation for both reproducible and repeatable forensic ${ }^{2} \mathrm{H}$ isotope analysis of human hair by continuous flow isotope ratio mass spectrometry. Rapid Commun. Mass Spectrom. 25, 3331-3338.

Münzel, M.C., Rivals, F., Pacher, M., Döppes, D., Rabeder, G., Conard, N.J., Drucker, D.G., Bocherens, H., 2014. Behavioural ecology of Late Pleistocene cave bears (Ursus spelaeus, $U$. ingressus): insights from stable isotopes $(\mathrm{C}, \mathrm{N}, \mathrm{O})$ and tooth microwear. Quat. Int. 339-340, 148-163.
Naito, Y.I., Chikaraishi, Y., Drucker, D.G., Ohkouchi, N., Semal, P., Wißing, C., Bocherens, H, 2016. Ecological niche of Neanderthals from Spy Cave revealed by nitrogen isotopes of individual amino acids in collagen. J. Hum. Evol. 93, 82-90.

Peigné, S., Goillot, C., Germonpré, M., Blondel, C., Bignon, O., Merceron, G., 2009. Predormancy omnivory in European cave bears evidenced by a dental microwear analysis of Ursus spelaeus from Goyet, Belgium. Proc. Natl. Acad. Sci. 106 15390-15393.

Pietsch, S.J., Hobson, K.A., Wassenaar, L.I., Tütken, T., 2011. Tracking cats: problems with placing feline carnivores on $\delta^{18} \mathrm{O}, \delta \mathrm{D}$ Isoscapes. PLoS One 6, e24601.

Reynard, L.M., Hedges, R.E.M., 2008. Stable hydrogen isotopes of bone collagen in palaeodietary and palaeoenvironmental reconstruction. J. Archaeol. Sci. 35 1934-1942.

Richards, M.P., Trinkaus, E., 2009. Isotopic evidence for the diets of European Neanderthals and early modern humans. Proc. Natl. Acad. Sci. 106, 16034-16039.

Sauer, P.E., Schimmelmann, A., Sessions, A.L., Topalov, K., 2009. Simplified batch equilibration for $\mathrm{D} / \mathrm{H}$ determination of non-exchangeable hydrogen in solid organic material. Rapid Commun. Mass Spectrom. 23, 949-956.

Schwartz-Narbonne, R., Longstaffe, F.J., Metcalfe, J.Z., Zazula, G., 2015. Solving the woolly mammoth conundrum: amino acid ${ }^{15} \mathrm{~N}$-enrichment suggests a distinct forage or habitat. Sci. Rep. 5, 9791.

Topalov, K., Schimmelmann, A., Polly, P.D., Sauer, P.E., Lowry, M., 2013. Environmental, trophic, and ecological factors influencing bone collagen $\delta^{2} \mathrm{H}$. Geochim. Cosmochim. Acta $111,88-104$

van Hardenbroek, M., Gröcke, D.R., Sauer, P.E., Elias, S.A., 2012. North American transect of stable hydrogen and oxygen isotopes in water beetles from a museum collection. J. Paleolimnol. 48, 461-470.

Wassenaar, L.I., Hobson, K.A., Sisti, L., 2015. An online temperature-controlled vacuumequilibration preparation system for the measurement of $\delta^{2} \mathrm{H}$ values of non-exchangeable- $\mathrm{H}$ and of $\delta^{18} \mathrm{O}$ values in organic materials by isotope-ratio mass spectrometry. Rapid Commun. Mass Spectrom. 29, 397-407. 